\title{
The Impact of Liquidity on GARCH Option Pricing Error during Financial Crisis
}

\author{
Han Ching Huang ${ }^{1}$, Yong Chern $\mathrm{Su}^{2}$, Wei-Shen $\mathrm{Chen}^{2}$ \\ ${ }^{1}$ Department of finance, Chung Yuan Christian University, Taoyuan, Taiwan \\ ${ }^{2}$ Department of finance, National Taiwan University, Taipei, Taiwan \\ Correspondence: Han Ching Huang, Department of Finance, Chung Yuan Christian University, Taoyuan, Taiwan.
}

Received: June 1, 2017

doi:10.11114/aef.v4i4.2513

Accepted: June 18, 2017 Available online: June 25, 2017

URL: https://doi.org/10.11114/aef.v4i4.2513

\begin{abstract}
In this paper, we explore the valuation performance of Heston and Nandi GARCH (HN GARCH) model on the pricing of options of financial stocks listed for AMEX during pre and post financial crisis periods. We find that the GARCH pricing model presents better performance than the traditional Black-Scholes model for the out-of-sample option pricing, no matter what the moneyness and the time-to-maturity. Specifically, the models show the effects of liquidity is not significant. Intuitionally, smaller liquidity tends to exhibit more pricing errors, especially for longer mature options. Unfortunately, we cannot get the expected outcomes, which is that the period of post financial crisis tend to have larger pricing errors. In sum, except more computational convenience, the HN GARCH model offers another vision of the relationship between liquidity and its effect on pricing errors.
\end{abstract}

Keywords: GARCH option pricing model, HN GARCH model, liquidity, financial crisis

\section{Introduction}

The Black-Scholes model (1973) assumes that asset prices can be modeled as geometric Brownian motion and follow a log-normal distribution with constant volatility. A direct result of these assumptions is that all options on the same asset should have the same implied volatility, since they are all based on the same underlying asset. Fama (1965) and Mandelbrot (1966), however, found that stock returns tend to have issues of fat-tailed marginal distributions and volatility clustering. Moreover, it has been shown in actual practice that Black-Scholes implied volatilities for options on the assets are not constant. They actually vary depending on the specific exercise prices and time to maturity of the options. It has been conjectured that Black-Scholes model fails to correctly capture the underlying factors affecting the option prices due to its assumption of constant volatility. Naturally, this weakness of the Black-Sholes model has been suggested as evidence of the existence of stochastic volatility of financial asset prices. In response to this weakness, many of the researchers have tried to develop original models to try to capture this stochastic volatility of financial asset prices over the last two decades. Hence, it is worthwhile to examine whether these models based on the assumption of stochastic volatility of financial asset prices actually improve the performance of the Black-Scholes model.

Given that volatility is not observable, an alternative way is to use one option implied volatility to price other options. Nevertheless, the above way is prone to error, when the option's volume is low. Therefore, GARCH model is preferred.

Duan (1995) incorporated GARCH into a discrete-time model and proposed the GARCH option pricing model to extend the Black-Scholes model. The model belongs to a family of ARCH models first introduced by Engle (1982) and later improved upon by Bollerslev (1986) as the GARCH model. The main hypothesis of the GARCH model is conditional heteroskedasticity, with variance determined by a series of parameters and a sequence of random variables that are noise. To further capture the negative correlation between returns and conditional volatility, Engle and $\mathrm{Ng}$ (1993) presented the nonlinear GARCH, or NGARCH model.

However, there are less closed-form solutions for option prices on most GARCH models. Heston and Nandi (2000) developed a closed-form GARCH model for European option. Specifically, their model is suitable for multiple lags in the time series dynamics of the variance process and correlation between the returns of the spot asset and variance.

Based on HN GARCH model in the American Stock Exchange (henceforth AMEX), we compare its pricing errors with those of the Black-Scholes model. According to Su, Huang, and Fung (2011) and Su, Chen, and Huang (2010), the GARCH model 
demonstrates smaller out-of-sample valuation errors compared to the Black-Scholes model with slight modifications.

In addition to the comparison of the out-of-sample valuation errors of the GARCH model and Black-Scholes model, this paper also investigate the influence of the liquidity of the underlying asset on the option pricing error pre and post the financial crisis. It is reasonable to consider the liquidity of the underlying asset. The higher liquidity of an asset is associated with the least information asymmetry. Thus, the smaller the pricing errors we can expect. The most important is that, however, the models presented in this paper show the effects of liquidity is not significant. Generally speaking, greater liquidity results in less pricing errors, especially for the long mature options. Unfortunately, we cannot get the expected outcomes, which is that the period of post financial crisis tend to have larger pricing errors.

This paper is organized as follows. In Section 2, we present the data and methodology. Section 3 provides the empirical results. Section 4 concludes.

\section{Data and Methodology}

\subsection{Data Description}

The sample time series data which has been analyzed in this paper were obtained from Option Metrics in Wharton Research Data Services (WRDS). The sample series data consist of time series of reported closing prices of American options as well as the stock prices of a total of seven companies. These are Bank of America, Citigroup, Goldman Sachs, ING Groep, JP Morgan Chase, Morgan Stanly, and Wells Fargo. Because of the financial industry was the origin of the financial crisis, all samples are chosen from the financial industry. Table 1 presents the summary statistics.

Moreover, the sample data is divided into two parts. The first part is from 06/17/2008 to 09/17/2008, and the other part is from $09 / 18 / 2008$ to $12 / 18 / 2008$ for a total of 65 trading days respectively. What we use to split these two parts is the beginning of the financial crisis, which is thought to be the date of the collapse of Lehman Brothers. To make the computations feasible, it is assumed that dividends paid out by these companies are zero and need not be subtracted from their stock prices. We use the continuously compounded Treasury bill rates as the risk free rate.

Table 1. Summary Statistics

\begin{tabular}{llcl}
\hline Name of company & $\begin{array}{l}\text { Average three } \\
\text { trading volume(in million) }\end{array}$ & $\begin{array}{c}\text { Market capitalization } \\
\text { (in billion) }\end{array}$ & Price to earning ratio \\
\hline Bank of America & 138.34 & 124.42 & N/A \\
Citigroup & 422.05 & 133.37 & 12.97 \\
Goldman Sachs & 4.78 & 82.61 & 11.46 \\
ING Groep & 2.07 & 49.86 & 14.37 \\
JP Morgan Chase & 29.9 & 181.68 & 10.13 \\
Morgan Stanley & 11.61 & 39.54 & 9.95 \\
Wells Fargo & 36.06 & 153.35 & 13.17
\end{tabular}

We restrict to only analyze call options in this paper. In addition, an option is sampled when it is suitable for the following standards. First, to ensure a certain level of credibility, we eliminate the deeply out-of-money (OTM) and in-the-money (ITM) options. That is, we delete the call options with K/S, lower than 0.95 or higher than 1.05 . Second, to ensure the active trading of the options, we only use those options with volume no less than 100 contracts.

Therefore, the number of observations is 14024. Further, we divide the sample into ten groups according to their moneyness and time to maturity. In the light of moneyness, the sample is cataloged into three parts: ITM $(0.95 \leq K / S<0.99)$, at-the-money (ATM, $0.99 \leq K / S<1.01)$, and OTM $(1.01 \leq K / S<1.05)$. We further base on their time to maturity to classify: short-term (not greater than to 30 days) and long term (greater than 30 days).

Moreover, the daily historical closing stock prices, from 06/17/2007 to 06/16/2008, are used to estimate the parameters of the GARCH process.

\subsection{The Model}

This section presents the option pricing process based on the closed form GARCH option valuation model (Heston and Nandi, 2000). The HN GARCH model provides a more applicable solution for the real option market instead of slow and computationally intensive simulations given by traditional GARCH models. Two assumptions should be made in the HN GARCH model. First, the log-spot prices obey a GARCH process. Second, the value of a call option one period before expiration obeys the Black-Scholes-Rubinstein (hereafter BSR) formula. We use a BSR formula for the spot price follows a conditionally lognormal distribution. BSR follows this up with the following propositions: 


\section{Proposition 1:}

Let $f(\phi)$ denote the conditional generating function of the asset price, as the following shows:

$$
f(\phi)=E_{t}\left\lfloor S(T)^{\phi}\right\rfloor
$$

This is also the moment generating function of $\log (S(T))$. It should be noted that, while $f(\phi)$ actually depends on the parameters and state variables of the model, these are omitted for notational convenience. In addition, $f(\phi)$ will also be used to denote the generating function of the risk-neutral process.

Proposition 2:

The generating function takes the log-linear form

$$
f(\phi)=S(T)^{\phi} \cdot \exp \left(A(t ; T, \phi)+\sum_{i=1}^{p} B_{i}(t ; T, \phi) h(t+2 \Delta-i \Delta)+\sum_{i=1}^{q-1} C_{i}\left(z(t+\Delta-i \Delta)-\gamma_{i} \sqrt{h(t+\Delta-i \Delta)}\right)^{2}\right)
$$

where

$$
\begin{aligned}
& A(t ; T, \phi)=A(t+\Delta ; T, \phi)+\phi \Delta+B_{1}(t+\Delta ; T, \phi) \omega-\frac{1}{2} \ln \left(1-2 \alpha_{1} B_{1}(t+\Delta ; T, \phi)\right) \\
& B_{1}(t ; T, \phi)=\phi\left(\lambda+\gamma_{1}\right)-\frac{1}{2} \gamma_{1}^{2}+\beta_{1} B_{1}(t+\Delta ; T, \phi)+\frac{1 / 2\left(\phi-\gamma_{1}\right)^{2}}{1-2 \alpha_{1} B_{1}(t+\Delta ; T, \phi)}
\end{aligned}
$$

for the single lag (i.e. $p=q=1$ ) version, and these coefficients can be computed recursively using the following boundary conditions:

$$
\begin{aligned}
& A(T ; T, \phi)=0 \\
& B_{1}(T ; T, \phi)=0
\end{aligned}
$$

Since the generating function of $S(T)$ is the moment generating function of $\log (S(T)), f(i \phi)$ is the characteristic function of $\log (S(T))$. The risk-neutral probabilities may then be calculated by inverting the characteristic function. This leads naturally to another proposition.

Proposition 3:

If the characteristic function of the log spot price is $f(i \phi)$, then

$$
E_{t}[\operatorname{Max}(S(t)-K, 0)]=f(1)\left(\frac{1}{2}+\frac{1}{\pi} \int_{0}^{\infty} \operatorname{Re}\left[\frac{K^{-i \phi} f(i \phi+1)}{i \phi f(1)}\right] d \phi\right)-K\left(\frac{1}{2}+\frac{1}{\pi} \int_{0}^{\infty} \operatorname{Re}\left[\frac{K^{-i \phi} f(i \phi)}{i \phi}\right] d \phi\right)
$$

where Re denotes the real part of a complex number.

The price of an option is then simply the discounted expected value of future payoff, $\operatorname{Max}(\mathrm{S}(\mathrm{T})-\mathrm{K}, 0)$, calculated using the risk-neutral probabilities. In other words, the option value may be easily calculated by replacing $f(i \phi)$ with $f^{*}(i \phi)$ in the equations above. The value of a European option may then be established through the following corollary.

\section{Empirical Results}

The empirical analysis starts with the estimation of GARCH model by Maximum Likelihood Estimation (MLE) with time series data on stock returns in section 2. Section 3 follows up with model comparisons between Black-Scholes and GARCH for out-of-sample time series data.

\subsection{Estimation}

GARCH model is used to model the evolution of volatility. Thus, all parameters can be estimated directly from the past stock prices. The estimation is done with the MLE method used by Bollerslev (1986). In addition, we run the estimation twice for an unrestricted model and a restricted model. This estimation is performed on the data of time series of stock prices from Jun. $17^{\text {th }}, 2007$ to Jun. $16^{\text {th }}, 2008$. Figures 1 and 2 present the annualized volatility of the unrestricted model 
and a restricted model for the sample period.

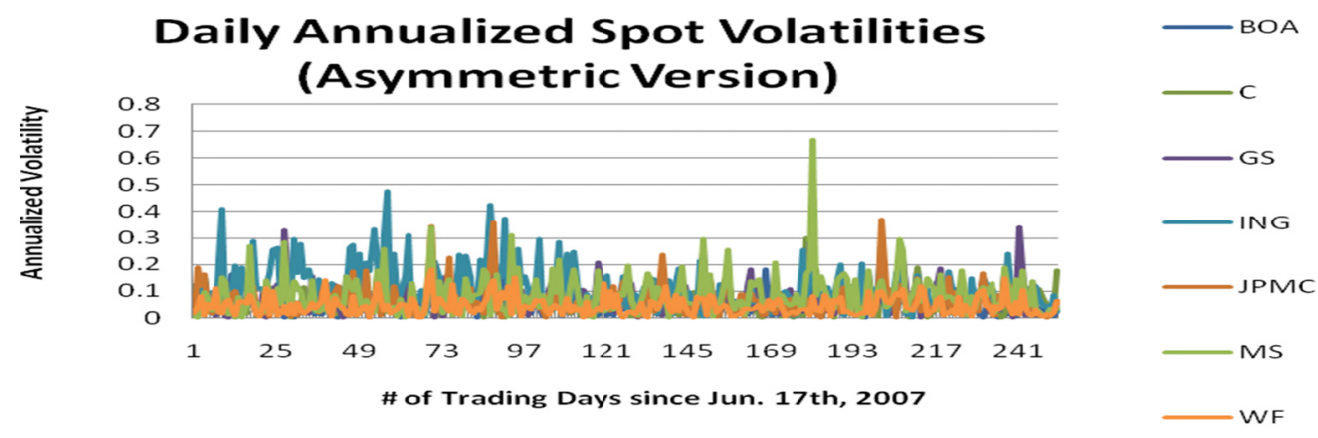

Figure 1. The daily annualized spot volatilities from the asymmetric GARCH model

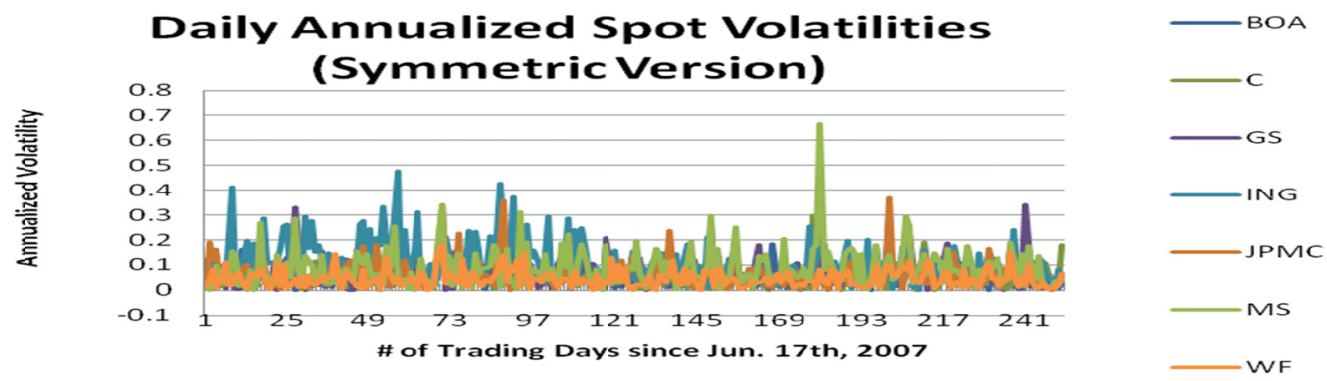

Figure 2. The daily annualized spot volatilities from the symmetric GARCH model

The volatility of volatility, as indicated by parameter $\alpha_{1}$, is very small for all companies, being no more than 0.016 in

all cases. Moreover, the parameter used to measure the degree of mean reversion, $\beta_{1}+\alpha_{1} \gamma_{1}^{2}$, is between 0.5 and 0.9 for most of the firms in both two models, implying that mean reversion is strong. Compared with other company, ING Group has relatively smaller mean reversion, which is $0.2039,0.2810,0.2034$, and 0.17718 . The inadequacy of mean reversion can be argued by its large $\mathrm{P} / \mathrm{E}$ ratio. The annualized long-run mean of volatility, or $\theta$ in the tables, are quite low for both models. A similar conclusion may be drawn by examining the Figures 1 and 2, where the annualized levels of $\sqrt{h(t+1)}$ are not significantly different. This can best be explained by the fact that the skewness parameter's not being significantly different from zero by the likelihood ratio test. We use the above parameters to compute the option prices. As Su, Huang, and Fung (2011) showed, the above pricing process is annoyed with significant errors. Therefore, some corrections would be discussed in the next section.

\subsection{Out-of-sample Comparison}

We use the data in the sample period of 06/17/2007 to 06/16/2008 to estimate the GARCH option model pricing parameters. Then, we use the above parameters to forecast the option prices during the out-of-sample period before and after the financial crisis, which is Jun. $17^{\text {th }}, 2008$ to Dec. $18^{\text {th }}, 2008$. The implied parameters are supposed to be constant over each week of computation. We use three loss functions, which are mean absolute errors (MAE), mean percentage errors (MPE), and root mean squared errors (RMSE), to objectively compare the models' effectiveness. The loss functions are defined as follows. 


$$
\begin{aligned}
& M A E=\frac{1}{N} \sum_{i=1}^{N}\left|C_{\text {model }}^{i}-C_{\text {market }}^{i}\right| \\
& M P E=\frac{1}{N} \sum_{i=1}^{N} \frac{\left(C_{\text {mod } e l}^{i}-C_{\text {market }}^{i}\right)}{C_{\text {market }}^{i}} \\
& \text { RMSE }=\sqrt{\frac{1}{N} \sum_{i=1}^{N}\left(C_{\text {model }}^{i}-C_{\text {market }}^{i}\right)^{2}}
\end{aligned}
$$

where $C_{\text {model }}^{i}$ is the computed price of call option i, $C_{\text {market }}^{i}$ is the market price of call option i, $N$ is the number of contracts involved.

Relative Pricing Errors for Call Options (ToM $\leqq 30$ )

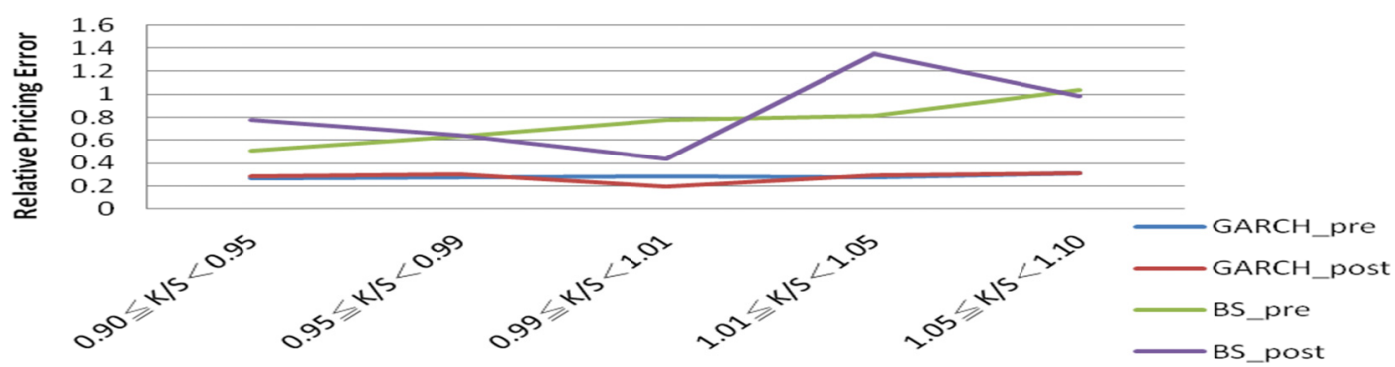

Figure 3. The comparison of pricing error on options of maturity of less than 30 days for Bank of America

Relative Pricing Errors for Call Options (ToM > 30)

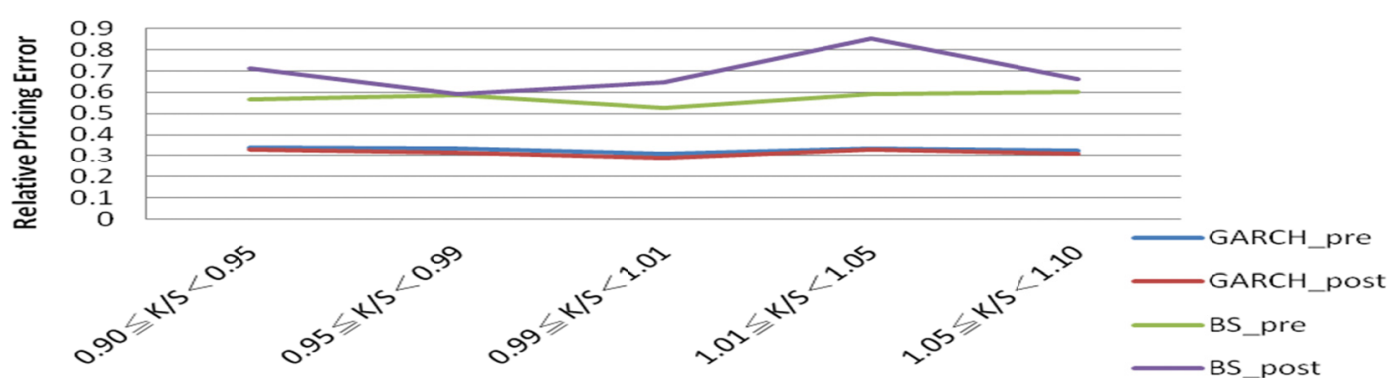

Figure 4. The comparison of pricing error on options of maturity of more than 30 days for Bank of America

Tables 2 to 4 report the out-of-sample valuation errors of 7 different companies before and after the financial crisis for various models. Figures 3 and 4 depict this comparison for Bank of America graphically. ${ }^{1}$ According to these tables and figures, the GARCH model outperforms the BS in most of the time to maturity and moneyness categories for all the companies, where BS and GARCH models have been suggested by Su, Chen, and Huang (2010) and Su, Huang, and Fung (2011) to fair less impressively. Specifically, the volatilities of the pricing errors for the options with longer time-to-maturity are greater than those with shorter time to maturity for almost all companies.

American options are more flexible than their European counterparts. Although European options display more volatility as the expired day comes near, American options show different patterns. The long time-to-maturity is associated with the more possible expired day. Therefore, American options show greater volatility.

Moreover, liquidity does not make a difference between pre and post financial crisis. No matter what the trade volume they are, comparing the pairs of the results of ING Group (small trade volume) or Goldman Sachs (moderate trade volume), as well as Bank of America (great trade volume), no obvious conclusion can drawn from the pricing errors between pre and post financial crisis.

Using MAE and RMSE as the pricing errors, we find that the option's price in the post financial crisis with lower liquidity is more accurate priced in Bank of America, especially for long term options. Nonetheless, the similar results cannot be found in ING Group and Goldman Sachs. It is worth noting that the options of Bank of America and Morgan

${ }^{1}$ The comparisons for other companies by graph are upon request. 
Stanley, in the period of post financial crisis, are more accurately priced than the period of pre financial crisis, which is inconsistent with the rationale in earlier sections. Due to the infrequency trading, the call options with lower liquidity behave more like European options, whose volatilities are smaller than American options.

Last but not least, Wells Fargo features the greatest errors in pricing (as measured by MAE and RMSE) of all the companies in the period of pre financial crisis.

Table 2. The out-of-sample pricing errors proxied by MAE

\begin{tabular}{|c|c|c|c|c|c|c|c|}
\hline \multirow{2}{*}{ Bank of America } & \multirow[t]{2}{*}{ Model } & \multicolumn{2}{|c|}{ ITM } & \multicolumn{2}{|c|}{ АТМ } & \multicolumn{2}{|c|}{ OTM } \\
\hline & & $\mathrm{BS}$ & GARCH & $\mathrm{BS}$ & GARCH & $\mathrm{BS}$ & GARCH \\
\hline \multirow[t]{2}{*}{ Pre Crisis } & $\mathrm{ToM} \leqq 30$ & 1.44 & 0.006 & 1.374 & 0.074 & -0.401 & -0.026 \\
\hline & ToM $>30$ & 1.714 & 0.004 & 1.37 & -0.044 & 1.182 & 0.014 \\
\hline \multirow[t]{2}{*}{ Post Crisis } & $\mathrm{ToM} \leqq 30$ & -0.528 & 0.02 & -1.537 & 0.039 & -0.701 & 0.054 \\
\hline & ToM $>30$ & 1.696 & 0.004 & 1.849 & 0.01 & 2.126 & 0.018 \\
\hline \multicolumn{8}{|l|}{ Citigroup } \\
\hline \multirow[t]{2}{*}{ Pre Crisis } & $\mathrm{ToM} \leqq 30$ & -0.264 & -0.004 & -0.494 & 0.011 & -0.472 & -0.017 \\
\hline & ToM $>30$ & -0.13 & 0.024 & -0.189 & -0.002 & -0.159 & 0.006 \\
\hline \multirow[t]{2}{*}{ Post Crisis } & $\mathrm{ToM} \leqq 30$ & -0.444 & -0.02 & -0.625 & -0.033 & -0.573 & -0.043 \\
\hline & ToM $>30$ & -0.408 & 0.015 & -0.411 & 0 & -0.435 & 0 \\
\hline \multicolumn{8}{|l|}{ Goldman Sachs } \\
\hline \multirow[t]{2}{*}{ Pre Crisis } & $\mathrm{ToM} \leqq 30$ & -0.313 & -0.017 & -0.344 & -0.018 & 0.054 & 0.002 \\
\hline & ToM $>30$ & -0.121 & -0.001 & -0.102 & -0.005 & -0.101 & -0.005 \\
\hline \multirow[t]{2}{*}{ Post Crisis } & $\mathrm{ToM} \leqq 30$ & -0.537 & -0.008 & -0.633 & 0.031 & -0.636 & 0.002 \\
\hline & ToM $>30$ & -0.4 & 0.006 & -0.41 & 0.011 & -0.422 & -0.007 \\
\hline \multicolumn{8}{|l|}{ ING Group } \\
\hline \multirow[t]{2}{*}{ Pre Crisis } & $\mathrm{ToM} \leqq 30$ & -0.298 & 0.02 & -0.368 & 0 & -0.63 & -0.05 \\
\hline & ToM $>30$ & -0.089 & 0.002 & -0.146 & -0.017 & -0.172 & 0.025 \\
\hline \multirow[t]{2}{*}{ Post Crisis } & $\mathrm{ToM} \leqq 30$ & -0.546 & 0.018 & -0.597 & 0.05 & -0.775 & 0 \\
\hline & ToM $>30$ & -0.555 & 0.012 & -0.522 & -0.045 & -0.655 & -0.053 \\
\hline \multicolumn{8}{|l|}{ JP Morgan } \\
\hline \multirow[t]{2}{*}{ Pre Crisis } & $\mathrm{ToM} \leqq 30$ & 2.19 & 0.002 & 1.457 & 0.008 & 1.018 & 0.012 \\
\hline & ToM $>30$ & 1.482 & -0.009 & 2.755 & -0.004 & 2.466 & -0.011 \\
\hline \multirow[t]{2}{*}{ Post Crisis } & $\mathrm{ToM} \leqq 30$ & 1.006 & 0.006 & 0.572 & -0.013 & 1.893 & -0.007 \\
\hline & ToM $>30$ & 1.84 & -0.002 & 1.678 & 0.004 & 1.75 & -0.003 \\
\hline \multicolumn{8}{|l|}{ Morgan Stanley } \\
\hline \multirow[t]{2}{*}{ Pre Crisis } & $\mathrm{ToM} \leqq 30$ & -0.416 & 0.004 & -0.464 & -0.029 & -0.474 & 0.012 \\
\hline & ToM $>30$ & -0.176 & -0.005 & -0.16 & 0.008 & -0.153 & 0 \\
\hline \multirow[t]{2}{*}{ Post Crisis } & $\mathrm{ToM} \leqq 30$ & -0.583 & 0.01 & -0.729 & 0.005 & -0.762 & -0.041 \\
\hline & ToM $>30$ & -0.476 & -0.011 & -0.56 & -0.01 & -0.568 & 0.003 \\
\hline \multicolumn{8}{|l|}{ Wells Fargo } \\
\hline \multirow[t]{2}{*}{ Pre Crisis } & $\mathrm{ToM} \leqq 30$ & 0.234 & -0.513 & 0.438 & -0.573 & 1.204 & -0.692 \\
\hline & ToM $>30$ & -0.282 & -0.29 & -0.243 & -0.3 & -0.049 & -0.315 \\
\hline \multirow[t]{2}{*}{ Post Crisis } & $\mathrm{ToM} \leqq 30$ & -0.551 & -0.018 & -0.656 & 0.029 & -0.724 & -0.006 \\
\hline & ToM $>30$ & -0.408 & -0.006 & -0.446 & -0.002 & -0.474 & -0.004 \\
\hline
\end{tabular}


Table 3. The out-of-sample pricing errors proxied by MPE

\begin{tabular}{|c|c|c|c|c|c|c|c|}
\hline \multirow{2}{*}{ Bank of America } & \multirow[t]{2}{*}{ Model } & \multicolumn{2}{|c|}{ ITM } & \multicolumn{2}{|c|}{ ATM } & \multicolumn{2}{|c|}{ OTM } \\
\hline & & $\overline{\mathrm{BS}}$ & GARCH & BS & GARCH & BS & GARCH \\
\hline \multirow[t]{2}{*}{ Pre Crisis } & $\mathrm{ToM} \leqq 30$ & 1.546 & 0.581 & 1.083 & 0.338 & 1.212 & 0.385 \\
\hline & ToM $>30$ & 2.222 & 1.268 & 1.884 & 1.079 & 2.022 & 1.123 \\
\hline \multirow[t]{2}{*}{ Post Crisis } & $\mathrm{ToM} \leqq 30$ & 1.358 & 0.549 & 3.543 & 1.346 & 1.795 & 0.477 \\
\hline & ToM $>30$ & 2.439 & 1.105 & 2.218 & 0.786 & 2.704 & 0.977 \\
\hline \multicolumn{8}{|l|}{ Citigroup } \\
\hline \multirow[t]{2}{*}{ Pre Crisis } & $\mathrm{ToM} \leqq 30$ & 0.485 & 0.146 & 0.482 & 0.1 & 0.354 & 0.077 \\
\hline & ToM $>30$ & 0.53 & 0.318 & 0.507 & 0.288 & 0.38 & 0.258 \\
\hline \multirow[t]{2}{*}{ Post Crisis } & $\mathrm{ToM} \leqq 30$ & 0.76 & 0.145 & 1.186 & 0.182 & 0.658 & 0.104 \\
\hline & ToM $>30$ & 1.245 & 0.318 & 1.236 & 0.321 & 1.091 & 0.275 \\
\hline \multicolumn{8}{|l|}{ Goldman Sachs } \\
\hline \multirow[t]{2}{*}{ Pre Crisis } & $\mathrm{ToM} \leqq 30$ & 3.736 & 1.232 & 2.679 & 0.842 & 1.902 & 0.548 \\
\hline & ToM $>30$ & 2.783 & 2.476 & 2.153 & 2.142 & 2.067 & 1.892 \\
\hline \multirow[t]{2}{*}{ Post Crisis } & $\mathrm{ToM} \leqq 30$ & 5.917 & 1.078 & 5.565 & 0.894 & 5.351 & 0.76 \\
\hline & ToM $>30$ & 8.366 & 2.263 & 7.992 & 2.154 & 7.747 & 2.04 \\
\hline \multicolumn{8}{|l|}{ ING Group } \\
\hline \multirow[t]{2}{*}{ Pre Crisis } & $\mathrm{ToM} \leqq 30$ & 0.685 & 0.205 & 0.536 & 0.131 & 0.448 & 0.075 \\
\hline & ToM $>30$ & 0.277 & 0.188 & 0.387 & 0.28 & 0.446 & 0.236 \\
\hline \multirow[t]{2}{*}{ Post Crisis } & $\mathrm{ToM} \leqq 30$ & 0.876 & 0.157 & 0.599 & 0.108 & 0.741 & 0.096 \\
\hline & ToM $>30$ & 1.531 & 0.282 & 1.398 & 0.243 & 1.581 & 0.251 \\
\hline \multicolumn{8}{|l|}{ JP Morgan } \\
\hline \multirow[t]{2}{*}{ Pre Crisis } & $\mathrm{ToM} \leqq 30$ & 1.557 & 0.294 & 1.653 & 0.262 & 0.902 & 0.145 \\
\hline & $\mathrm{ToM}>30$ & 1.893 & 0.473 & 2.208 & 0.417 & 1.826 & 0.349 \\
\hline \multirow{2}{*}{ Post Crisis } & $\mathrm{ToM} \leqq 30$ & 1.9 & 0.327 & 1.652 & 0.244 & 1.441 & 0.182 \\
\hline & ToM $>30$ & 3.004 & 0.63 & 2.793 & 0.567 & 2.954 & 0.499 \\
\hline \multicolumn{8}{|l|}{ Morgan Stanley } \\
\hline \multirow[t]{2}{*}{ Pre Crisis } & $\mathrm{ToM} \leqq 30$ & 1.478 & 0.361 & 1.189 & 0.268 & 0.859 & 0.193 \\
\hline & $\mathrm{ToM}>30$ & 1.204 & 0.653 & 0.967 & 0.567 & 0.892 & 0.51 \\
\hline \multirow[t]{2}{*}{ Post Crisis } & $\mathrm{ToM} \leqq 30$ & 1.646 & 0.273 & 1.925 & 0.265 & 1.728 & 0.224 \\
\hline & ToM $>30$ & 2.477 & 0.544 & 2.763 & 0.517 & 2.531 & 0.465 \\
\hline \multicolumn{8}{|l|}{ Wells Fargo } \\
\hline \multirow[t]{2}{*}{ Pre Crisis } & $\mathrm{ToM} \leqq 30$ & 3.295 & 1.443 & 3.078 & 1.189 & 3.136 & 0.953 \\
\hline & ToM $>30$ & 4.768 & 1.337 & 4.018 & 1.169 & 4.142 & 1.103 \\
\hline \multirow[t]{2}{*}{ Post Crisis } & $\mathrm{ToM} \leqq 30$ & 1.873 & 0.338 & 1.718 & 0.266 & 1.603 & 0.226 \\
\hline & ToM $>30$ & 2.553 & 0.658 & 2.534 & 0.598 & 2.444 & 0.545 \\
\hline
\end{tabular}


Table 4. The out-of-sample pricing errors proxied by RMSE

\begin{tabular}{|c|c|c|c|c|c|c|c|}
\hline \multirow{2}{*}{ Bank of America } & \multirow{2}{*}{ Model } & \multicolumn{2}{|c|}{ ITM } & \multicolumn{2}{|c|}{ ATM } & \multicolumn{2}{|c|}{ OTM } \\
\hline & & BS & GARCH & BS & GARCH & BS & GARCH \\
\hline \multirow[t]{2}{*}{ Pre Crisis } & $\mathrm{ToM} \leqq 30$ & 1.593 & 0.688 & 1.176 & 0.429 & 1.308 & 0.445 \\
\hline & ToM $>30$ & 2.539 & 1.446 & 2.053 & 1.212 & 2.194 & 1.248 \\
\hline \multirow[t]{2}{*}{ Post Crisis } & $\mathrm{ToM} \leqq 30$ & 1.523 & 0.708 & 2.459 & 1.104 & 2.964 & 0.637 \\
\hline & ToM $>30$ & 2.557 & 1.35 & 2.294 & 1.032 & 3.389 & 1.311 \\
\hline \multicolumn{8}{|l|}{ Citigroup } \\
\hline \multirow[t]{2}{*}{ Pre Crisis } & $\mathrm{ToM} \leqq 30$ & 0.516 & 0.149 & 0.538 & 0.104 & 0.393 & 0.082 \\
\hline & ToM $>30$ & 0.587 & 0.331 & 0.655 & 0.303 & 0.429 & 0.275 \\
\hline \multirow[t]{2}{*}{ Post Crisis } & $\mathrm{ToM} \leqq 30$ & 0.894 & 0.159 & 1.345 & 0.198 & 0.779 & 0.121 \\
\hline & ToM $>30$ & 1.317 & 0.332 & 1.338 & 0.336 & 1.163 & 0.29 \\
\hline \multicolumn{8}{|l|}{ Goldman Sachs } \\
\hline \multirow[t]{2}{*}{ Pre Crisis } & $\mathrm{ToM} \leqq 30$ & 3.976 & 1.253 & 2.904 & 0.864 & 2.426 & 0.597 \\
\hline & ToM $>30$ & 3.446 & 2.604 & 2.731 & 2.295 & 2.774 & 2.065 \\
\hline \multirow[t]{2}{*}{ Post Crisis } & $\mathrm{ToM} \leqq 30$ & 6.513 & 1.149 & 5.973 & 0.949 & 5.934 & 0.835 \\
\hline & ToM $>30$ & 8.792 & 2.368 & 8.352 & 2.287 & 8.234 & 2.177 \\
\hline \multicolumn{8}{|l|}{ ING Group } \\
\hline \multirow[t]{2}{*}{ Pre Crisis } & $\mathrm{ToM} \leqq 30$ & 0.862 & 0.212 & 0.686 & 0.139 & 0.483 & 0.078 \\
\hline & ToM $>30$ & 0.448 & 0.254 & 0.508 & 0.288 & 0.671 & 0.25 \\
\hline \multirow{2}{*}{ Post Crisis } & $\mathrm{ToM} \leqq 30$ & 1.076 & 0.184 & 0.708 & 0.114 & 0.936 & 0.12 \\
\hline & ToM $>30$ & 1.661 & 0.305 & 1.592 & 0.26 & 1.658 & 0.268 \\
\hline \multicolumn{8}{|l|}{ JP Morgan } \\
\hline \multirow[t]{2}{*}{ Pre Crisis } & $\mathrm{ToM} \leqq 30$ & 1.915 & 0.332 & 2.119 & 0.305 & 1.202 & 0.181 \\
\hline & ToM $>30$ & 2.546 & 0.546 & 2.961 & 0.503 & 2.684 & 0.428 \\
\hline \multirow{2}{*}{ Post Crisis } & $\mathrm{ToM} \leqq 30$ & 1.993 & 0.357 & 1.766 & 0.275 & 1.691 & 0.233 \\
\hline & ToM $>30$ & 3.22 & 0.691 & 3.002 & 0.631 & 3.338 & 0.574 \\
\hline \multicolumn{8}{|l|}{ Morgan Stanley } \\
\hline \multirow[t]{2}{*}{ Pre Crisis } & $\mathrm{ToM} \leqq 30$ & 1.535 & 0.365 & 1.229 & 0.272 & 0.911 & 0.201 \\
\hline & ToM $>30$ & 1.774 & 0.682 & 1.468 & 0.595 & 1.48 & 0.549 \\
\hline \multirow[t]{2}{*}{ Post Crisis } & $\mathrm{ToM} \leqq 30$ & 1.882 & 0.303 & 2.132 & 0.292 & 2.037 & 0.259 \\
\hline & ToM $>30$ & 2.569 & 0.567 & 2.84 & 0.542 & 2.636 & 0.489 \\
\hline \multicolumn{8}{|l|}{ Wells Fargo } \\
\hline \multirow[t]{2}{*}{ Pre Crisis } & $\mathrm{ToM} \leqq 30$ & 4.526 & 1.48 & 5.146 & 1.234 & 5.091 & 1.011 \\
\hline & ToM $>30$ & 5.724 & 1.493 & 4.619 & 1.299 & 5.152 & 1.237 \\
\hline \multirow[t]{2}{*}{ Post Crisis } & $\mathrm{ToM} \leqq 30$ & 1.99 & 0.35 & 1.774 & 0.276 & 1.718 & 0.24 \\
\hline & ToM $>30$ & 2.696 & 0.678 & 2.665 & 0.621 & 2.583 & 0.573 \\
\hline
\end{tabular}

\section{Conclusions}

In this paper, we compare the valuation performance of GARCH model on the pricing of options of AMEX financial stocks between the pre and post financial crisis periods. The obvious observation is that the GARCH pricing model presents better performance than the traditional Black-Scholes model for the out-of-sample option pricing, no matter what the moneyness and the time-to-maturity.

Although the GARCH model outperforms the other model, its valuation errors for ITM options are relatively high, especially when the time-to-maturity is more than 30 days. The reason for this inaccuracy might be that the sample period is either too long to include noise or too short to capture fully the volatilities.

The most important is that, however, the models presented in this paper show the effects of liquidity is not significant. Generally speaking, smaller liquidity is prone to show more pricing errors, particularly for long term option. Unfortunately, we cannot get the expected outcomes, which is that the period of post financial crisis tend to have larger pricing errors. This may be that smaller liquidity induces that trading rarely happen. The behaviors of options with smaller liquidity are more like European options, Therefore, the HN GARCH model can more accurately model their pricing.

In all, while Heston \& Nandi GARCH model provide more computational convenient than other more optimal models, it still provides some useful vision of the relationship between liquidity and its effect on pricing errors.

\section{References}

Black, K., \& Scholes, M. (1973). The Pricing of Options and Corporate Liabilities. Journal of Political Economy, 81, 637-659. https://dx.doi.org/10.1086/260062

Bollerslev, T. (1986). Generalized Autoregressive Conditional Heteroskedasticity. Journal of Econometrics, 31, 307-327. https://dx.doi.org/10.1016/0304-4076(86)90063-1

Duan, J. (1995). The GARCH Option Pricing Model. Mathematical Finance, 5, 13-32. https://doi.org/10.1111/j.1467-9965.1995.tb00099.x 
Engle, R. (1982). Autoregressive Conditional Heteroscedasticity with Estimates of the Variance of United Kingdom Inflation. Econometrica, 50, 987-1008. https://doi.org/10.1111/j.1540-6261.1993.tb05127.x

Engle, R. F., \& Ng, V. K. (1993). Measuring and testing the impact of news on volatility. Journal of Finance, 48, 1749-1778. https://dx.doi.org/10.2307/2329066

Fama, E. (1965). The Behavior of Stock Market Prices. Journal of Business, 38, 34-105. https://dx.doi.org/10.1086/294743

Heston, S., \& Nandi, S. (2000). A Closed-Form GARCH Option Valuation Model. Review of Financial Studies, 13, 585-625. https://doi.org/10.1093/rfs/13.3.585

Mandelbrot, B. (1966). Forecasts of Future Prices, Unbiased Markets and Martingale Models. Journal of Business, 39, 242-255. https://dx.doi.org/10.1086/294850

Su, Y. C., Chen, M. D., \& Huang, H. C. (2010). An Application of Closed-Form GARCH Option Pricing Model on FTSE 100 Option and Volatility. Applied Financial Economics, 20, 899-910. https://dx.doi.org/10.1080/09603101003652417

Su, Y. C., Huang, H. C., \& Fung, C. P. (2011). An Application of Closed-Form GARCH Option Pricing Model to TAIEX Options and Volatilities. Empirical Economics Letters, 10, 731-738.

https://dx.doi.org/10.1016/S0895-7177(01)00127-3

\section{Copyrights}

Copyright for this article is retained by the author(s), with first publication rights granted to the journal.

This is an open-access article distributed under the terms and conditions of the Creative Commons Attribution license which permits unrestricted use, distribution, and reproduction in any medium, provided the original work is properly cited. 